\title{
Inspiratory Fraction Correlates With Exercise Capacity in Patients With Stable Moderate to Severe COPD
}

\author{
Yan Zhang MD, Xing-Guo Sun MD, Wen-Lan Yang MD, \\ Xiao-Yue Tan MD, and Jin-Ming Liu MD
}

\begin{abstract}
BACKGROUND: Exercise intolerance is the hallmark of COPD. Static lung hyperinflation and increased dynamic hyperinflation during exercise are associated with reduced functional capacity in COPD patients. Inspiratory capacity correction for the total lung capacity, defined as inspiratory fraction (IF), may be functionally more representative than other traditional indices in these patients. OBJECTIVE: To investigate the association between IF and exercise capacity in patients with stable, moderate to severe COPD. METHODS: Fifty COPD subjects and 34 healthy volunteers constituted the study cohort. Pulmonary function and cardiopulmonary exercise testing were performed, and ventilation and gas exchange parameters were measured. RESULTS: IF was significantly correlated with percent-of-predicted peak oxygen consumption $\left(\dot{\mathrm{V}}_{\mathrm{O}_{2}}\right)$ in the subjects with COPD $(r=0.52, P<.001)$. IF was an independent predictor of reduced exercise capacity in the COPD subjects, and was more sensitive and specific than percent-of-predicted FEV $_{1}$. Statistical analysis generated the equation: percent-of-predicted peak $\dot{\mathrm{V}}_{\mathrm{O}_{2}}=65.9 \mathrm{IF}+\mathbf{0 . 4 5}$ percent-of-predicted $\mathrm{FEV}_{1}+35.8\left(\mathrm{R}_{\mathrm{C}}{ }^{2}=0.39, P<.001\right)$. The subjects with $\mathrm{IF}<0.23$ had more severe lung hyperinflation and less exercise capacity than the subjects with IF $>0.23$. At peak exercise, the breathing frequencies of the 2 groups were similar, whereas the low-IF subjects had reduced peak minute ventilation and peak tidal volume, relative to the high-IF subjects. CONCLUSIONS: Compared to $\mathrm{FEV}_{1}$, IF is a robust factor to reflect lung hyperinflation and to estimate the exercise capacity of subjects with stable moderate to severe COPD. Key words: COPD; inspiratory fraction; lung hyperinflation; cardiopulmonary exercise test; inspiratory capacity. [Respir Care 2013;58(11): 1923-1930. (c) 2013 Daedalus Enterprises]
\end{abstract}

\section{Introduction}

COPD is recognized as the fourth leading cause of death worldwide and a major chronic respiratory disorder due to different diseases causing medical disability. COPD is characterized by air-flow limitation that is poorly reversible,

The authors are affiliated with the Department of Respiratory Medicine, Shanghai Pulmonary Hospital, Tongji University, Shanghai, China, with the exception of Dr Sun, who is affiliated with the Los Angeles Biomedical Research Institute at Harbor-UCLA Medical Center, Torrance, California.

The authors have disclosed no conflicts of interest.

Correspondence: Jin-Ming Liu MD, Department of Respiratory Medicine, Shanghai Pulmonary Hospital, Tongji University, 507 Zhengmin Road, Shanghai 200433, China. E-mail: jinmingliu_sh@ hotmail.com.

DOI: $10.4187 /$ respcare.01927 progressive, and associated with an abnormal inflammatory response of the lung to noxious particles, such as the materials released from smoking. ${ }^{1}$ The hallmark of COPD is exercise intolerance and exertional dyspnea, which are due to complex interactions between impaired ventilatory, cardiovascular, and peripheral muscle responses. The major abnormality of respiratory muscle dysfunction in COPD patients is the mechanical disadvantage caused by lung hyperinflation. Static lung hyperinflation at rest and increased dynamic hyperinflation during exercise are associated with reduced functional capacity in these patients. ${ }^{2}$ Over the decades, it has been widely accepted that traditional measures of air-flow obstruction, such as $\mathrm{FEV}_{1}$ and $\mathrm{FEV}_{1} / \mathrm{FVC}$, are repeatable and reliable for the diagnosis and prognosis of COPD. However, increasing evidence demonstrates that $\mathrm{FEV}_{1} / \mathrm{FVC}$ does not reflect the level of lung hyperinflation and is poorly correlated with exercise capacity and exertional dyspnea in COPD patients. ${ }^{1,2}$ 
Recently, inspiratory capacity (IC) at rest and during exercise has been shown to be superior to traditional predictive parameters like $\mathrm{FEV}_{1} .{ }^{3} \mathrm{IC}$ reflects the level of lung hyperinflation and is associated with the functional reserve in patients with COPD. Moreover, the ratio of IC to total lung capacity (IC/TLC, called the inspiratory fraction or IF) provides a better characterization of the volume fraction available for inspiration than does IC alone, ${ }^{4}$ and IF predicts exercise capacity in patients with moderate to severe COPD. In the current study we compared the functional parameters of ventilation, gas exchange, and exercise capacity in patients with stable moderate to severe COPD. We also analyzed the breathing patterns and exertional dyspnea of these patients with standard pulmonary function tests (PFTs) and cardiopulmonary exercise testing (CPET). Our objective was to investigate the relationship between IC, IF, and other parameters and the exercise capacity of patients with COPD, to determine if IF is a robust predictor of exercise capacity in COPD patients.

\section{Methods}

The protocol was approved by our hospital's ethics review board. All subjects signed written informed consent before enrollment. Patients diagnosed as having COPD stage II $(n=16)$ and stage III $(n=34)$ at the Department of Respiratory Medicine, Shanghai Pulmonary Hospital, between July 2010 and June 2011, were recruited for this study. Diagnosis and classification were based on the Global Initiative for Chronic Obstructive Lung Disease 2010 guidelines. ${ }^{5}$ All subjects accepted regular treatment and had stable COPD for at least 4 weeks prior to enrollment. More than 400 patients were screened for this study, by analyzing patient history, PFTs, heart color Doppler ultrasound, and computed tomograms. Patients with other diseases that cause breathing discomfort and impaired exercise capacity, such as asthma, pulmonary arterial hypertension, interstitial lung disease, other concomitant lung disease, heart failure, metabolic disorders, and/or skeletal muscle diseases, were excluded. As a control group, 34 healthy volunteers of similar ages participated in the study. Professional athletes and laborers were excluded.

Age, sex, body weight, and height of all subjects were recorded, and body mass index was calculated. PFTs were performed (MasterScreen-PFT, Erich Jaeger, Friedberg, Germany) before and after bronchodilator. Every subject completed at least 3 acceptable tests, with an interval of $1 \mathrm{~min}$. The variability between the 3 tests was $<5 \%$, and the results of the best trial were recorded. Collected parameters included $\mathrm{FVC}, \mathrm{FEV}_{1}, \mathrm{FEV}_{1} / \mathrm{FVC}$, maximal voluntary ventilation (MVV), IC, TLC, residual volume (RV), RV/TLC, and diffusing capacity of the lung for carbon

\section{QUICK LOOK}

\section{Current knowledge}

Exercise intolerance is common and decreases quality of life in patients with COPD. Static lung hyperinflation and increased dynamic hyperinflation during exercise reduce functional capacity in COPD patients.

\section{What this paper contributes to our knowledge}

Inspiratory fraction (inspiratory capacity/total lung capacity) independently predicted reduced exercise capacity in patients with moderate to severe COPD. An inspiratory fraction of $>0.23$ was associated with worse lung hyperinflation and reduced exercise capacity.

monoxide $\left(\mathrm{D}_{\mathrm{LCO}}\right)$ (corrected for hemoglobin). PFT parameters are expressed as percent-of-predicted values, which were calculated using the equations designed for Chinese adults in $1988 .^{6}$

Symptom-limited CPET was conducted on a cycle ergometer, using a cardiopulmonary exercise testing system (MasterScreen-CPX, Erich Jaeger, Friedberg, Germany) and a gas analysis system (SBx/CPX, Erich Jaeger, Friedberg, Germany). ${ }^{7}$ The increasing work rate was individually selected from $10 \mathrm{~W} / \mathrm{min}$ to $25 \mathrm{~W} / \mathrm{min}$, to provide a total exercise duration of $8-12$ min. During the whole procedure we monitored a 12-lead online electrocardiogram, blood pressure, $\mathrm{S}_{\mathrm{pO}_{2}}$, and gas exchange. Gas exchange data were recorded, breath-by-breath, and averaged over 10-second intervals, followed by further analysis. ${ }^{8-10}$ The tests were terminated if the subject had any of the following conditions: ischemic electrocardiogram changes (ST depression of $2 \mathrm{~mm}$ with chest pain, or $\mathrm{ST}$ depression of $3 \mathrm{~mm}$ without chest pain), frequent premature ventricular contractions, conduction disorders, systolic pressure $>250 \mathrm{~mm} \mathrm{Hg}$, diastolic pressure $>120 \mathrm{~mm} \mathrm{Hg}$, a fall in systolic pressure $>20 \mathrm{~mm} \mathrm{Hg}$ from the highest value obtained during the test, and/or an $\mathrm{S}_{\mathrm{pO}_{2}}<80 \%$. Typical symptoms for stopping were leg fatigue, weakness, or shortness of breath. The CPET variables were peak load, peak oxygen uptake $\left(\dot{\mathrm{V}}_{\mathrm{O}_{2}}\right)$, peak $\mathrm{O}_{2}$ pulse, minute ventilation $\left(\dot{\mathrm{V}}_{\mathrm{E}}\right)$, breathing frequency, tidal volume $\left(\mathrm{V}_{\mathrm{T}}\right)$, heart rate, and heart rate reserve (predicted heart rate - peak heart rate) (predicted heart rate $=220$ age). Anaerobic threshold was determined by the V-slope method. ${ }^{11}$ The intensity of dyspnea at peak exercise was described as peak $\dot{\mathrm{V}}_{\mathrm{E}} / \mathrm{MVV}$. CPET parameters were expressed as percent-of-predicted values, which were calculated with the equations from the American Thoracic Society/American College of Chest Physicians in 2003. ${ }^{12}$ 
Table 1. Demographics and Pulmonary Function and Cardiopulmonary Exercise Testing Results From COPD Subjects Versus Normal Subjects

\begin{tabular}{|c|c|c|c|}
\hline & $\begin{array}{c}\text { COPD Subjects } \\
n=50\end{array}$ & $\begin{array}{c}\text { Normal Subjects } \\
n=34\end{array}$ & $P$ \\
\hline Male/female & $45 / 5$ & $26 / 8$ & .09 \\
\hline Age, y & $63 \pm 6$ & $60 \pm 7$ & .08 \\
\hline Body mass index, $\mathrm{kg} / \mathrm{m}^{2}$ & $23 \pm 3$ & $24 \pm 3$ & .12 \\
\hline FVC, $\%$ predicted & $84.82 \pm 14.5$ & $102.44 \pm 11.49$ & $<.001$ \\
\hline $\mathrm{FEV}_{1}, \%$ predicted & $46.48 \pm 11.88$ & $98.30 \pm 11.51$ & $<.001$ \\
\hline $\mathrm{FEV}_{1} / \mathrm{FVC}, \%$ & $44.05 \pm 7.42$ & $77.55 \pm 4.51$ & $<.001$ \\
\hline TLC, $\%$ predicted & $124.5 \pm 23.31$ & $103.27 \pm 7.82$ & .002 \\
\hline Inspiratory capacity, $\%$ predicted & $65.2 \pm 20.73$ & $91.34 \pm 21.0$ & .001 \\
\hline Inspiratory fraction & $0.25 \pm 0.07$ & $0.43 \pm 0.10$ & $<.001$ \\
\hline $\mathrm{RV}, \%$ predicted & $189.49 \pm 42.61$ & $109.82 \pm 10.18$ & $<.001$ \\
\hline $\mathrm{RV} / \mathrm{TLC}, \%$ & $58.89 \pm 7.7$ & $38.87 \pm 5.07$ & $<.001$ \\
\hline $\mathrm{D}_{\mathrm{LCO}}, \%$ predicted & $83.89 \pm 25.57$ & $108.0 \pm 25.0$ & .004 \\
\hline $\mathrm{P}_{\mathrm{aO}_{2}}, \mathrm{~mm} \mathrm{Hg}$ & $79 \pm 10$ & $90 \pm 2$ & $<.001$ \\
\hline $\mathrm{P}_{\mathrm{aCO}_{2}}, \mathrm{~mm} \mathrm{Hg}$ & $38 \pm 4$ & $36 \pm 2$ & .33 \\
\hline Peak work, W & $93 \pm 29$ & $137 \pm 33$ & $<.001$ \\
\hline Peak work, $\%$ predicted & $82.76 \pm 23.57$ & $115.68 \pm 20.89$ & $<.001$ \\
\hline Peak $\dot{\mathrm{V}}_{\mathrm{O}_{2}}, \mathrm{~mL} / \mathrm{min}$ & $1,279.72 \pm 301.86$ & $1,643.85 \pm 331.52$ & $<.001$ \\
\hline Peak $\dot{\mathrm{V}}_{\mathrm{O}_{2}}, \%$ predicted & $73.41 \pm 13.75$ & $91.71 \pm 12.13$ & $<.001$ \\
\hline Peak heart rate, beats/min & $133 \pm 19$ & $151 \pm 16$ & $<.001$ \\
\hline Peak $\dot{\mathrm{V}}_{\mathrm{E}}, \mathrm{L} / \mathrm{min}$ & $41.88 \pm 10.1$ & $60.74 \pm 15.27$ & $<.001$ \\
\hline Peak breathing frequency, breaths/min & $32 \pm 6$ & $34 \pm 6$ & .33 \\
\hline Peak $V_{T}, L$ & $1.33 \pm 0.36$ & $1.83 \pm 0.47$ & $<.001$ \\
\hline Peak $\mathrm{O}_{2}$ pulse, $\mathrm{mL} /$ beat & $9.62 \pm 1.68$ & $10.98 \pm 2.24$ & .002 \\
\hline Peak $\mathrm{O}_{2}$ pulse, $\%$ predicted & $91.31 \pm 13.53$ & $100.56 \pm 16.23$ & .006 \\
\hline Peak $\dot{\mathrm{V}}_{\mathrm{E}}$ /maximum voluntary ventilation & $1.04 \pm 0.19$ & $0.71 \pm 0.21$ & $<.001$ \\
\hline Anaerobic threshold, $\mathrm{mL} / \mathrm{min}$ & $956.48 \pm 215.69$ & $1,136.91 \pm 242.63$ & $<.001$ \\
\hline$\dot{\mathrm{V}}_{\mathrm{E}} / \dot{\mathrm{V}}_{\mathrm{CO}_{2}}$ at anaerobic threshold & $35.23 \pm 4.94$ & $30.69 \pm 3.67$ & $<.001$ \\
\hline $\begin{array}{l}\text { Values are mean } \pm \text { SD. } \\
\mathrm{TLC}=\text { total lung capacity } \\
\mathrm{RV}=\text { residual volume } \\
\mathrm{D}_{\mathrm{LCO}}=\text { diffusing capacity of the lung for carbon mon } \\
\dot{\mathrm{V}}_{\mathrm{E}}=\text { minute volume } \\
\dot{\mathrm{V}}_{\mathrm{O}_{2}}=\mathrm{O}_{2} \text { consumption } \\
\mathrm{V}_{\mathrm{T}}=\text { tidal volume } \\
\dot{\mathrm{V}}_{\mathrm{CO}_{2}}=\mathrm{CO}_{2} \text { clearance }\end{array}$ & & & \\
\hline
\end{tabular}

All statistical analyses were performed with statistics software (SPSS 19.0, SPSS, Chicago, Illinois). Data are expressed as mean $\pm \mathrm{SD}$. $P$ values between groups were calculated using the chi-square test or the unpaired Student $t$ test. Pearson correlation coefficients were calculated to assess the correlations between variables. Backward, stepwise, multiple linear regression was performed to determine the independent predictors. Receiver operating characteristic (ROC) curves were created for selected variables, to evaluate the sensitivity and specificity of PFT parameters as predictors for percent-of-predicted peak $\dot{\mathrm{V}}_{\mathrm{O}_{2}}{ }^{13}$ The Youden index was calculated to find the cutoffs for variables. The Youden index is defined as the maximum vertical distance between the ROC curve and the diagonal or chance line, and is calculated as maximum (sensitiv- ity + specificity -1$).{ }^{14}$ A $P$ value $<.05$ was considered statistically significant.

\section{Results}

\section{PFT and CPET Values}

Fifty subjects with stable, moderate or severe COPD and 35 healthy volunteers participated in this study. Table 1 shows the demographics of all the subjects and the results of PFTs and CPET. There were no significant differences between the 2 groups in sex, age, or body mass index. Percent-of-predicted $\mathrm{FEV}_{1}\left(\mathrm{FEV}_{1} \%\right)$ in the COPD subjects demonstrated moderate to very severe obstruction $\left(\mathrm{FEV}_{1} \%\right.$ range $\left.32-75 \%\right)$. Nearly all the COPD subjects 


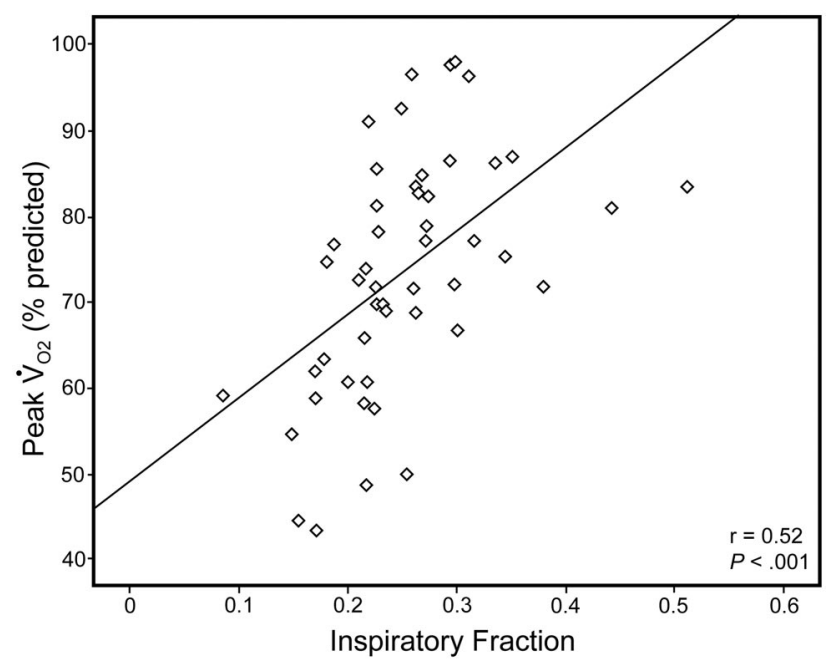

Fig. 1. Inspiratory fraction versus percent-of-predicted peak oxygen uptake $\left(\dot{\mathrm{V}}_{\mathrm{O}_{2}}\right)$ in subjects with stable, moderate to severe COPD.

had lung volume measurements suggestive of air trapping (percent-of-predicted RV range $129-296 \%, n=48$ ), and $\mathrm{D}_{\mathrm{LCO}}$ was decreased in nearly half (percent-of-predicted $\mathrm{D}_{\mathrm{LCO}} 37 \%$ to $79 \%, n=24$ ).

In the CPET we observed significant reductions in peak work, percent-of-predicted peak work, peak $\dot{\mathrm{V}}_{\mathrm{O}_{2}}$, percentof-predicted peak $\dot{\mathrm{V}}_{\mathrm{O}_{2}}$, and anaerobic threshold in the COPD subjects, compared to the normal subjects $(P<.001)$. Twenty-six percent of the COPD subjects displayed a severe reduction in percent-of-predicted peak $\dot{\mathrm{V}}_{\mathrm{O}_{2}}(<65 \%$, $n=13) .{ }^{10}$ The ratio of $\dot{\mathrm{V}}_{\mathrm{E}}$ to $\mathrm{CO}_{2}$ production $\left(\dot{\mathrm{V}}_{\mathrm{E}} / \dot{\mathrm{V}}_{\mathrm{CO}_{2}}\right)$ at anaerobic threshold in the COPD subjects was significantly higher than in the normal subjects. At peak exercise, gas exchange analysis showed that there was no significant difference for peak breathing frequency between the 2 groups $(P=.33)$. However, peak $\dot{V}_{\mathrm{E}}(44.95 \pm 12.94 \mathrm{~L} /$ min) and peak $\mathrm{V}_{\mathrm{T}}(1.43 \pm 0.39 \mathrm{~L})$ in the COPD subjects were dramatically decreased, compared to the control group $(60.74 \pm 15.27 \mathrm{~L} / \mathrm{min}$ and $1.83 \pm 0.47 \mathrm{~L}$, respectively, $P<.001)$. The peak $\dot{\mathrm{V}}_{\mathrm{E}} / \mathrm{MVV}$ of $98 \%$ of the COPD subjects was $>0.7$, suggesting a severely reduced breathing reserve in the COPD subjects at peak exercise. ${ }^{12}$ Moreover, the peak $\dot{\mathrm{V}}_{\mathrm{E}} / \mathrm{MVV}$ of the COPD subjects was worse than the control group $(1.04 \pm 0.19$ and $0.71 \pm 0.21$, respectively, $P<.001)$.

\section{Association Between PFT Parameters and Percent-of- Predicted Peak $\dot{\mathrm{V}}_{\mathrm{O}_{2}}$ in the COPD Subjects}

The percent-of-predicted peak $\dot{\mathrm{V}}_{\mathrm{O}_{2}}$ was significantly related to some PFT parameters, including percent-of-predicted IC (IC\%) $(\mathrm{r}=0.43, P=.002)$, percent-of-predicted $\mathrm{RV}(\mathrm{r}=-0.52, P<.001)$, percent-of-predicted TLC

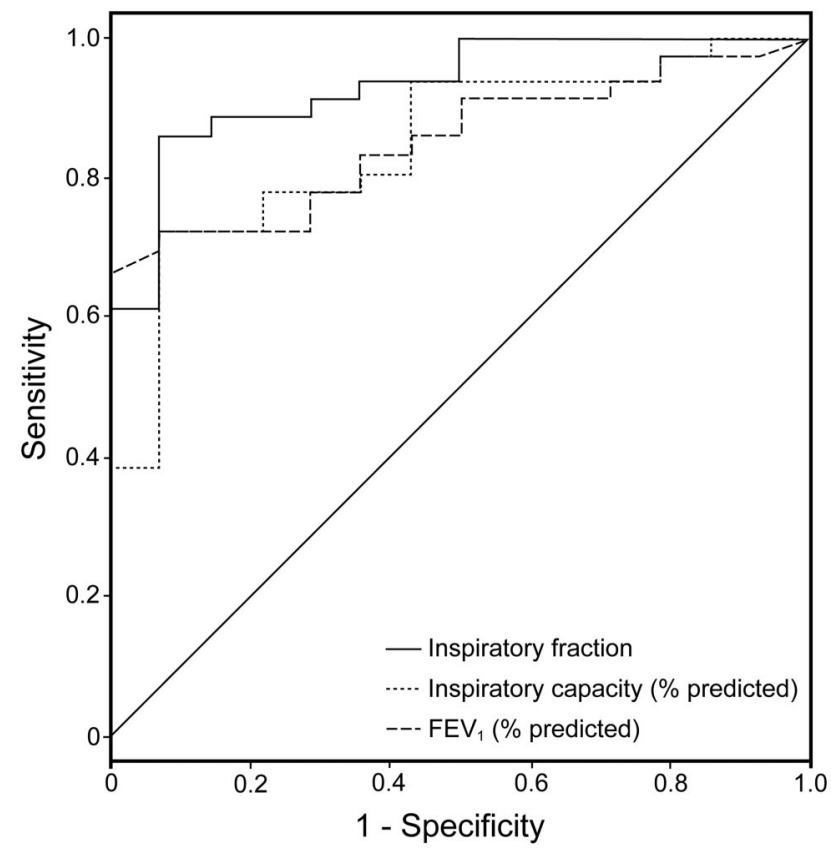

Fig. 2. Receiver operating characteristic curves for inspiratory fraction, percent-of-predicted inspiratory capacity, and percent-ofpredicted $\mathrm{FEV}_{1}$ for predicting the change in percent-of-predicted peak oxygen uptake $(<65 \%)$. The areas under the curve are 0.933 (95\% Cl 0.862-1.000, $P<.001), 0.849$ (95\% Cl 0.737-0.962, $P<.001)$, and 0.853 (95\% $\mathrm{Cl} 0.751-0.955, P<.001)$, and the cutoffs are $0.23,43 \%$, and $60 \%$, respectively.

( $\mathrm{r}=-0.25, P=.08), \mathrm{IF}(\mathrm{r}=0.52, P<.001$, Fig. 1$)$, and $\mathrm{FEV}_{1} \%(\mathrm{r}=0.54, P<.001)$. Backward stepwise multiple linear regression analysis generated the equation:

Percent-of-predicted peak $\dot{\mathrm{V}}_{\mathrm{O}_{2}}$

$$
=65.9 \mathrm{IF}+0.45 \mathrm{FEV}_{1} \%+35.8
$$

$\mathrm{R}_{\mathrm{C}}^{2}$ (the adjusted determination coefficient) $=0.39$ and $P<.001$. The results reveal that IF and $\mathrm{FEV}_{1} \%$ are independent predictors of exercise capacity in COPD subjects.

\section{IF as a Predictor of Exercise Capacity in COPD Subjects}

Based on the above findings, we then compared the sensitivity and specificity of IF, IC\%, and $\mathrm{FEV}_{1} \%$ as predictors of percent-of-predicted peak $\dot{\mathrm{V}}_{\mathrm{O}_{2}}$ in the COPD subjects, by analyzing the ROC curves. The areas under the curve were 0.933 (95\% CI $0.862-1.00, P<.001), 0.849$ (95\% CI $0.737-0.962, P<.001)$, and 0.853 (95\% CI $0.751-0.955, P<.001$ ), respectively (Fig. 2). When we chose 0.23 as the cutoff for IF, the sensitivity, specificity, 
Table 2. Demographics and Pulmonary Function and Cardiopulmonary Exercise Testing Results From Subjects With Inspiratory Fraction Less Than Versus More Than 0.23 Inspiratory Fraction

\begin{tabular}{|c|c|c|c|}
\hline & $\begin{array}{l}<0.23 \\
n=18\end{array}$ & $\begin{array}{l}\geq 0.23 \\
n=32\end{array}$ & $P$ \\
\hline Age, y & $64 \pm 8$ & $62 \pm 7$ & .48 \\
\hline Body mass index, $\mathrm{kg} / \mathrm{m}^{2}$ & $22 \pm 3$ & $23 \pm 3$ & .18 \\
\hline FVC, $\%$ predicted & $79.03 \pm 11.22$ & $88.07 \pm 15.26$ & .03 \\
\hline $\mathrm{FEV}_{1}, \%$ predicted & $39.59 \pm 5.81$ & $50.36 \pm 12.7$ & .001 \\
\hline $\mathrm{FEV}_{1} / \mathrm{FVC}, \%$ & $40.43 \pm 5.93$ & $46.09 \pm 7.47$ & .008 \\
\hline TLC, $\%$ predicted & $138.04 \pm 29.66$ & $116.89 \pm 14.48$ & .001 \\
\hline Inspiratory capacity, $\%$ predicted & $52.97 \pm 11.25$ & $72.09 \pm 21.77$ & .001 \\
\hline Inspiratory fraction & $0.18 \pm 0.04$ & $0.29 \pm 0.06$ & $<.001$ \\
\hline $\mathrm{RV}, \%$ predicted & $222.58 \pm 35.77$ & $170.87 \pm 34.27$ & $<.001$ \\
\hline $\mathrm{RV} / \mathrm{TLC}, \%$ & $63.83 \pm 5.95$ & $56.25 \pm 7.27$ & $<.001$ \\
\hline $\mathrm{D}_{\mathrm{LCO}}, \%$ predicted & $64.98 \pm 25.21$ & $94.86 \pm 22.68$ & $<.001$ \\
\hline $\mathrm{P}_{\mathrm{aO}_{2}}, \mathrm{~mm} \mathrm{Hg}$ & $76 \pm 10$ & $81 \pm 9$ & .21 \\
\hline $\mathrm{P}_{\mathrm{aCO}_{2}}, \mathrm{~mm} \mathrm{Hg}$ & $39 \pm 4$ & $36 \pm 4$ & .04 \\
\hline Peak work, W & $71 \pm 23$ & $103 \pm 29$ & .001 \\
\hline Peak work, $\%$ predicted & $70.86 \pm 23.06$ & $89.46 \pm 21.4$ & .006 \\
\hline Peak $\dot{\mathrm{V}}_{\mathrm{O}_{2}}, \mathrm{~mL} / \mathrm{min}$ & $1,061.44 \pm 210.36$ & $1,402.49 \pm 276.65$ & $<.001$ \\
\hline Peak $\dot{\mathrm{V}}_{\mathrm{O}_{2}}, \%$ predicted & $62.57 \pm 11.97$ & $79.5 \pm 10.67$ & $<.001$ \\
\hline Peak heart rate, beats/min & $122 \pm 17$ & $139 \pm 18$ & .002 \\
\hline Peak heart rate, $\%$ predicted & $72.43 \pm 9.12$ & $81.8 \pm 9.72$ & .002 \\
\hline Heart rate reserve, beats/min & $34 \pm 15$ & $19 \pm 16$ & .002 \\
\hline Peak $\dot{V}_{\mathrm{E}}, \mathrm{L} / \mathrm{min}$ & $36.47 \pm 4.87$ & $44.93 \pm 11.03$ & .001 \\
\hline Peak breathing frequency, breaths/min & $33 \pm 6$ & $32 \pm 6$ & .29 \\
\hline Peak $V_{T}, L$ & $1.13 \pm 0.25$ & $1.45 \pm 0.37$ & .001 \\
\hline Peak $\mathrm{O}_{2}$ pulse, $\mathrm{mL} / \mathrm{beats}$ & $8.72 \pm 1.46$ & $10.12 \pm 1.6$ & .003 \\
\hline Peak $\mathrm{O}_{2}$ pulse, $\%$ predicted & $86.06 \pm 13.47$ & $94.27 \pm 12.84$ & .04 \\
\hline Peak $\dot{\mathrm{V}}_{\mathrm{E}}$ /maximum voluntary ventilation & $1.06 \pm 0.16$ & $1.04 \pm 0.21$ & .72 \\
\hline Anaerobic threshold, L/min & $856.9 \pm 210.95$ & $989.68 \pm 210.23$ & .09 \\
\hline$\dot{\mathrm{V}}_{\mathrm{E}} / \dot{\mathrm{V}}_{\mathrm{CO}_{2}}$ at anaerobic threshold & $37.93 \pm 4.69$ & $34.33 \pm 4.76$ & .045 \\
\hline Stopping reason, no. & & & .03 \\
\hline Breathing discomfort & 13 & 11 & \\
\hline Leg fatigue & 3 & 15 & \\
\hline Breathing discomfort and leg fatigue & 2 & 6 & \\
\hline $\begin{array}{l}\text { Values are mean } \pm \text { SD. } \\
\mathrm{TLC}=\text { total lung capacity } \\
\mathrm{RV}=\text { residual volume } \\
\mathrm{D}_{\mathrm{LCO}}=\text { diffusing capacity of the lung for carbon mon } \\
\mathrm{V}_{\mathrm{O}_{2}}=\mathrm{O}_{2} \text { consumption } \\
\dot{\mathrm{V}}_{\mathrm{E}}=\text { minute volume } \\
\mathrm{V}_{\mathrm{T}}=\text { tidal volume } \\
\dot{\mathrm{V}}_{\mathrm{CO}_{2}}=\mathrm{CO}_{2} \text { clearance }\end{array}$ & & & \\
\hline
\end{tabular}

and Youden index of IF as an independent factor were $0.923,0.837$, and 0.76 , respectively. Similarly, the cutoff for $\mathrm{FEV}_{1} \%$ was $43 \%$, and the sensitivity, specificity, and Youden index were $0.722,0.929$ and 0.651 , respectively. The cutoff of IC\% was $63 \%$ and the sensitivity, specificity, and Youden index were 0.722, 0.929, and 0.651, respectively. The data reveal that IF is the best factor among PFT parameters for predicting exercise capacity in COPD subjects.

\section{Comparison of PFT and CPET Parameters in COPD Subjects With High or Low IF}

According to the calculated Youden index, we chose 0.23 as the cutoff for IF, and divided the COPD subjects into 2 groups: $\mathrm{IF}<0.23(n=18)$, and IF $\geq 0.23(n=32)$. Table 2 shows the respective PFT parameters of the 2 groups: $\mathrm{FEV}_{1} \%$ was $39.59 \pm 5.81 \%$ and $50.36 \pm 12.7 \%$, percent-of-predicted TLC was $138.04 \pm 29.66 \%$ and 


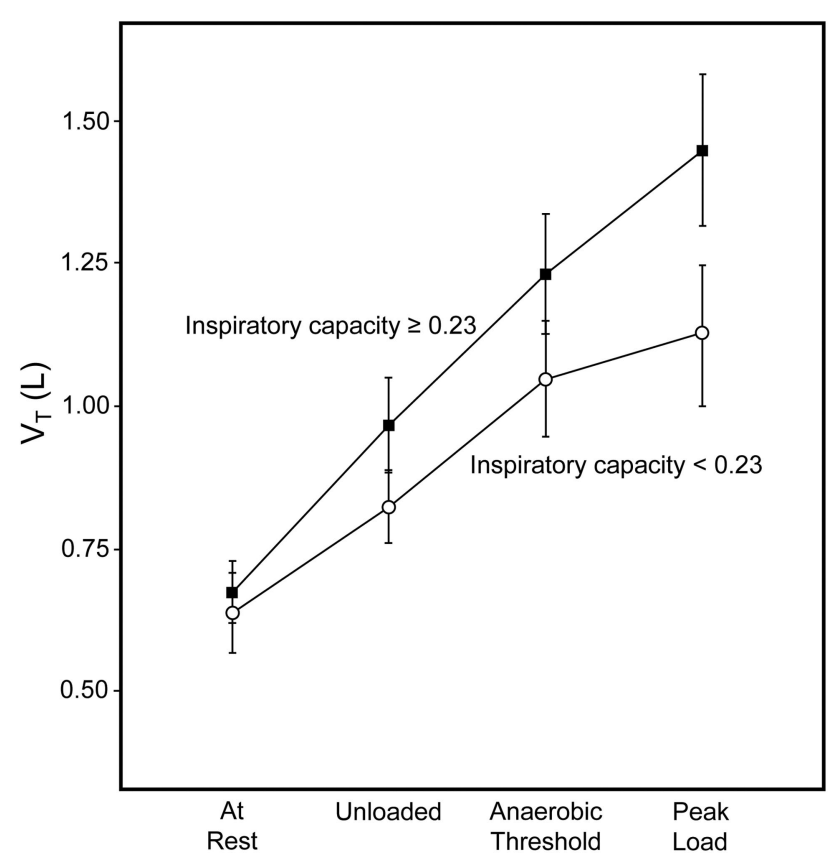

Fig. 3. Tidal volume $\left(\mathrm{V}_{\mathrm{T}}\right)$ during cardiopulmonary exercise testing in subjects with COPD and an inspiratory fraction $<0.23$ or $\geq 0.23$. The duration of rest was an average of $120 \mathrm{~s}$ before ending the period. The duration of warm-up was an average of $30 \mathrm{~s}$ before ending the period. The anaerobic threshold was determined by the $\mathrm{V}$-slope method. The duration of peak exercise was an average of $30 \mathrm{~s}$ before the peak load. The whisker bars indicate the $95 \% \mathrm{Cls}$. ${ }^{*} P<.05$.

$116.89 \pm 14.48 \%$, percent-of-predicted RV was $222.58 \pm 35.77 \%$ and $170.87 \pm 34.27 \%$, and IC\% was $52.97 \pm 11.25 \%$ and $72.09 \pm 21.77 \%$. These data suggest that the IF $<0.23$ group had worse air-flow obstruction and higher lung hyperinflation than the IF $\geq 0.23$ group.

The CPET results reveal that the peak percent-of-predicted $\dot{\mathrm{V}}_{\mathrm{O}_{2}}$ of 6 subjects in the IF $<0.23$ group was $>65 \%$, and that of the rest was $<65 \%$. The percent-of-predicted peak $\dot{\mathrm{V}}_{\mathrm{O}_{2}}$ of one subject in the IF $\geq 0.23$ group was $<65 \%$, and that of the rest was $>65 \%$. Breathing pattern analysis at peak exercise showed that the peak breathing frequency was not significantly different between the 2 COPD groups $(P=.29)$. However, the peak $\dot{\mathrm{V}}_{\mathrm{E}}(36.47 \pm 4.87 \mathrm{~L} / \mathrm{min})$ of the $\mathrm{IF}<0.23$ group was significantly lower than that of the IF $\geq 0.23$ group $(44.93 \pm 11.03 \mathrm{~L} / \mathrm{min})(P=.001)$, and $\mathrm{V}_{\mathrm{T}}$ at anaerobic threshold and peak exercise $(1.05 \pm 0.14 \mathrm{~L}$ and $1.13 \pm 0.25 \mathrm{~L}$ ) of the IF $<0.23$ group were significantly lower than those $(1.23 \pm 0.28 \mathrm{~L}$ and $1.45 \pm 0.37 \mathrm{~L})$ of the IF $\geq 0.23$ group $(P=.01$ and 0.001, Fig. 3 . $)$. The patterns of the change of $\mathrm{V}_{\mathrm{T}}$ and breathing frequency in CPET (Fig. 4) revealed that the $\mathrm{V}_{\mathrm{T}}$ of COPD subjects with $\mathrm{IF}<0.23$ did not increase substantially when the exercise load was increasing, and that $\mathrm{V}_{\mathrm{T}}$ at peak exercise almost reached the IC at rest. In contrast, the $\mathrm{V}_{\mathrm{T}}$ of COPD subjects with IF $>0.23$ increased when the exercise load was increasing, and the $\mathrm{V}_{\mathrm{T}}$ at peak
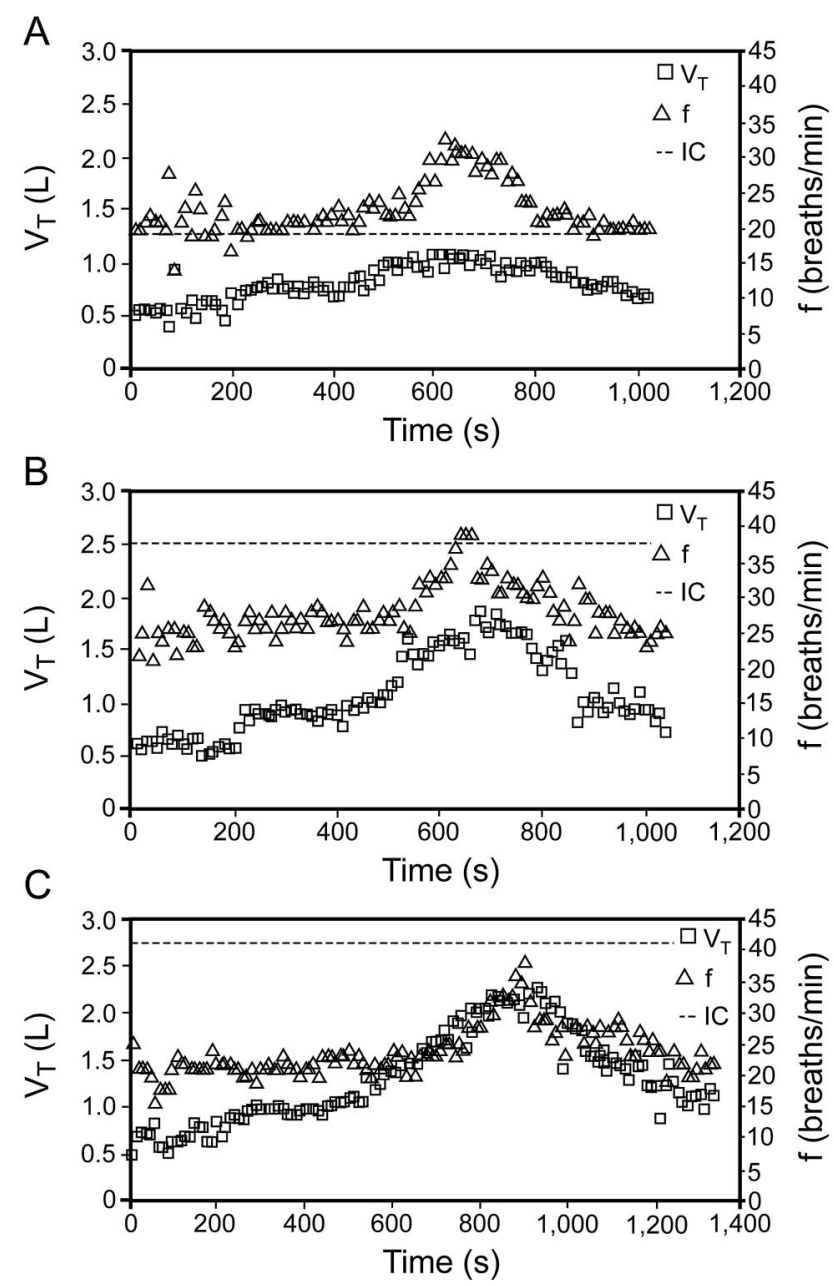

Fig. 4. Representative tidal volume $\left(\mathrm{V}_{\mathrm{T}}\right)$ and breathing frequency (f) patterns of subjects with COPD and normal subjects during cardiopulmonary exercise testing. A: COPD subject with inspiratory fraction (IF) 0.15 , inspiratory capacity (IC) 1.27 , and a $15 \mathrm{~W} / \mathrm{min}$ work increase. B: COPD subject with IF 0.35, IC 2.49, and a 20 W/ min work increase. C: Normal subject with IF 0.44, IC 2.73, and a $20 \mathrm{~W} / \mathrm{min}$ work increase.

exercise was lower than the IC at rest. The pattern of $\mathrm{V}_{\mathrm{T}}$ change in the IF $\geq 0.23$ group subjects was comparable to normal subjects, whereas the peak $\mathrm{V}_{\mathrm{T}}$ of the $\mathrm{IF} \geq 0.23$ group was smaller than that of control subjects. Gas exchange analysis showed that although anaerobic threshold was not statistically different between the 2 COPD groups $(P=.09)$, $\dot{\mathrm{V}}_{\mathrm{E}} / \dot{\mathrm{V}}_{\mathrm{CO}_{2}}$ was higher in the IF $<0.23$ group than the IF $\geq 0.23$ group ( $37.93 \pm 4.69$ vs $34.33 \pm 4.76, P=.045)$. In addition, $72 \%$ of COPD the IF $<0.23$ group subjects and $34 \%$ of the IF $\geq 0.23$ group subjects stopped exercise due to shortness of breath. $2 \%$ of the IF $<0.23$ group subjects and $47 \%$ of the $\mathrm{IF} \geq 0.23$ group subjects stopped the exercise because of leg fatigue. The results suggested that the reason for stopping exercise was significantly different between COPD subjects with high or low IF $(P<.05)$. 


\section{Discussion}

Although many factors contribute to exercise intolerance in COPD patients, such as impairment of pulmonary function, cardiovascular diseases, metabolic disorders, skeletal muscle diseases, or the combination of several diseases, one major reason is the limitation of pulmonary function. ${ }^{15}$ In the present study we excluded COPD patients with certain severe systemic diseases that impair pulmonary function and reduce exercise capacity.

As a key characteristic of decreased pulmonary function in COPD patients, expiratory flow reduction progressively promotes air trapping and lung hyperinflation, so COPD patients display decreased IC and increased RV and TLC. At rest these patients can extend the expiratory duration to fully exhale, but during exercise their only way to increase $\dot{\mathrm{V}}_{\mathrm{E}}$ is to increase breathing frequency, due to the limitation of the $\mathrm{V}_{\mathrm{T}}$ increment caused by a reduced IC. Therefore, the expiratory time is further decreased and lung hyperinflation and air trapping get worse. ${ }^{16}$ Meanwhile, increased end-expiratory lung volume in COPD patients leads to intrinsic PEEP, which increases the work of breathing and causes respiratory muscle fatigue and insufficient gas exchange during exercise. The combination of these events leads to limited exercise capacity and dyspnea. ${ }^{17}$

CPET with gas exchange analysis is a powerful technique to evaluate cardiovascular and pulmonary function. ${ }^{7} \mathrm{CPET}$ can noninvasively assess heart and lung function, exercise limitation, hypoperfusion of the lung and systemic circulation, and response to therapy, and help diagnose early pulmonary hypertension and assess surgery risk. The $\dot{\mathrm{V}}_{\mathrm{O}_{2}}$ increase measured at external respiration during exercise provides information on dynamic changes of internal metabolism. Moreover, peak $\dot{\mathrm{V}}_{\mathrm{O}_{2}}$ and percent-of-predicted peak $\dot{\mathrm{V}}_{\mathrm{O}_{2}}$ collected during symptom-limited CPET are the gold standard for evaluating exercise capacity. ${ }^{12}$ Our previous studies also demonstrated that dynamic oxygen uptake parameters during exercise are effective indices for evaluating heart and lung function in COPD patients. ${ }^{18,19} \mathrm{We}$ chose percentof-predicted peak $\dot{\mathrm{V}}_{\mathrm{O}_{2}}$ as a potential factor to evaluate exercise capacity. As an index for lung hyperinflation, IC is better than other PFT parameters in reflecting and predicting reduced exercise capacity and ventilation impairment in COPD patients. ${ }^{20-22}$ However, COPD patients with similar IC might have very different TLC, so IC/TLC is better than IC alone to reflect the increase of end-expiratory lung volume.

Our findings show that IF was significantly correlated with percent-of-predicted peak $\dot{\mathrm{V}}_{\mathrm{O}_{2}}$ and could be employed as an independent factor to predict reduced exercise capacity in patients with moderate to severe COPD. In addition, IF was more sensitive than IC\% in predicting exercise capacity in COPD patients, according to the ROC curve analysis. Our ROC curve analysis and Youden index calculation indicate that IF is also more sensitive than
$\mathrm{FEV}_{1} \%$ in predicting exercise capacity in COPD patients. This suggests that the change of lung hyperinflation is more predictive of the improvement of ventilation impairment than the change of expiratory air flow in stable COPD patients after treatment with bronchodilators. A group of studies showed that, compared to $\mathrm{FEV}_{1}$, IC was a potential factor in evaluating the effects of bronchodilators in COPD patients. ${ }^{23-25}$ The sensitivity, specificity, and Youden index of IF in predicting exercise capacity in COPD subjects were $0.861,0.929$, and 0.79 when 0.23 was selected as the IF cutoff. This suggests that 0.23 is a proper cutoff for IF as a predictor. Further comparison showed that the COPD subjects with IF $<0.23$ had worse lung hyperinflation, ventilation impairment, and exercise capacity reduction, indicating that IF is a robust predictor of COPD severity.

Our findings are consistent with those of Albuquerque et al, who reported that an IF 0.28 was a good predictor of exercise intolerance in COPD subjects. ${ }^{4}$ Also, Vassaux et al found that COPD subjects with an IF $<0.25$ possessed worse percent-of-predicted peak $\dot{\mathrm{V}}_{\mathrm{O}_{2}}$ and peak $\mathrm{O}_{2}$ pulse than subjects with an IF $>0.25 .{ }^{26}$ Another study found that IF was an independent predictor of mortality risk in COPD subjects, and that COPD subjects with an IF $<0.25$ had worse pulmonary function and higher mortality risk. ${ }^{27}$ The IF cutoff we found in our study was different from these other reports, which might be because of a different cohort size, different ethnicities of the subjects, and/or different COPD phenotypes.

Our CPET results showed no significant difference in peak breathing frequency between the 2 COPD groups. However, the peak $\mathrm{V}_{\mathrm{T}}$ and peak $\dot{\mathrm{V}}_{\mathrm{E}}$ of COPD subjects with an IF $<0.23$ were lower than those with an IF $\geq 0.23$. Seventy-two percent of the IF $<0.23$ group stopped the exercise due to shortness of breath, indicating that the limited $\mathrm{V}_{\mathrm{T}}$ increase was not sufficient to meet their ventilation demand during exercise, and the increased neuromuscular dissociation. We also noticed that (see Fig. 4), due to the reduction of IC, the increment of $\mathrm{V}_{\mathrm{T}}$ in the IF $<0.23$ group was significantly smaller than that in the IF $\geq 0.23$ group. Also, the $\mathrm{V}_{\mathrm{T}}$ in the IF $<0.23$ group was very close to their IC, indicating that subjects in the IF $<0.23$ group had more severe dynamic hyperinflation. Therefore, an increased respiratory muscle work in the $\mathrm{IF}<0.23$ group was required to overcome the lung dynamic elastance caused by gradually increasing endexpiratory lung volume..$^{28}$ Clearly, the only way of increasing exercise capacity in the IF $<0.23$ group was to increase the breathing frequency earlier, and they would stop exercise earlier because of respiratory distress. Meanwhile, a worse ventilation-to-perfusion ratio could have caused exertional dyspnea, thereby dramatically reducing exercise capacity. Because the $\dot{V}_{\mathrm{E}}$ and carbon dioxide production were simultaneously limited in the exercise, it was difficult to compare $\dot{V}_{\mathrm{E}} /$ $\dot{\mathrm{V}}_{\mathrm{CO}_{2}}$ at anaerobic threshold between the 2 COPD groups. In addition, the percent-of-predicted peak $\mathrm{O}_{2}$ pulse in the 
IF $<0.23$ group was less than that of the IF $\geq 0.23$ group. This might be caused by severe hyperinflation-induced reduction of left ventricular end-diastolic volume, reduced right heart blood volume, and/or increased left ventricular after-load. ${ }^{26,29}$

Due to our small sample size, we cannot rule out that another cutoff value of IF and other physiological variables might be superior to IF 0.23 to evaluate exercise capacity in patients with stable, moderate to severe COPD. The reasons for stopping exercise were significantly different between the 2 COPD groups, whereas there was no significant difference in peak $\dot{\mathrm{V}}_{\mathrm{E}} / \mathrm{MVV}$. It is possible that our cohort size was not big enough, or that the specificity of peak $\dot{\mathrm{V}}_{\mathrm{E}} / \mathrm{MVV}$ is not significant. Therefore, it is critical to further study the effects of dynamic hyperinflation on exercise capacity.

\section{Conclusions}

IF significantly correlates with and independently predicts exercise capacity in patients with stable, moderate to severe COPD. Compared to the COPD subjects with IF $>0.23$, the subjects with IF $<0.23$ had worse lung hyperinflation, less exercise capacity, and more reduced peak $\mathrm{V}_{\mathrm{T}}$, peak $\dot{\mathrm{V}}_{\mathrm{E}}$, and percent-of-predicted peak $\mathrm{O}_{2}$ pulse. Our findings support the hypothesis that IF is a useful predictor of exercise capacity in COPD patients, and might help physicians choose individual treatment plans.

\section{ACKNOWLEDGMENTS}

We thank the study participants and the technicians of our pulmonary function laboratory.

\section{REFERENCES}

1. Cooper CB. The connection between chronic obstructive pulmonary disease symptoms and hyperinflation and its impact on exercise and function. Am J Med 2006;119(10 Suppl 1):21-31.

2. Bauerle O, Chrusch CA, Younes M. Mechanisms by which COPD affects exercise tolerance. Am J Respir Crit Care Med 1998;157(1):57-68.

3. Diaz O, Villafranca C, Ghezzo H, Borzone G, Leiva A, Milic-Emil $\mathrm{J}$, et al. Role of inspiratory capacity on exercise tolerance in COPD patients with and without tidal expiratory flow limitation at rest. Eur Respir J 2000;16(2):269-275.

4. Albuquerque AL, Nery LE, Villaca DS, Machado TY, Oliveira CC, Paes AT, et al. Inspiratory fraction and exercise impairment in COPD patients GOLD stages II-III. Eur Respir J 2006;28(5):939-944.

5. Global Initiative for Chronic Obstructive Lung Disease. Global strategy for the diagnosis, management, and prevention of chronic obstructive pulmonary disease. Updated 2008. http://www.goldcopd. com/download.asp?intId=504. Accessed August 19, 2013.

6. Mu K, Liu S. Summary of Chinese pulmonary function normal values. Beijing Medical University and Peking Union Medical College Press; 1990:83-86.

7. Wasserman K, E. Hansen J, Sue DY, Stringer WW, J. Whipp B. Principles of exercise testing and interpretation: including pathophysiology and clinical applications, 4th edition. Philadelphia: Lippincott Williams \& Wilkinks 2008;133-159.

8. Sun XG, Hansen JE, Beshai JF, Wasserman K. Oscillatory breathing and exercise gas exchange abnormalities prognosticate early mortality and morbidity in heart failure. J Am Coll Cardiol 2010;55(17):18141823.

9. Sun XG, Hansen JE, Garatachea N, Storer TW, Wasserman K. Ventilatory efficiency during exercise in healthy subjects. Am J Respir Crit Care Med 2002;166(11):1443-1448.

10. Sun XG, Hansen JE, Oudiz RJ, Wasserman K. Exercise pathophysiology in patients with primary pulmonary hypertension. Circulation 2001;104(4):429-435.

11. Beaver WL, Wasserman K, Whipp BJ. A new method for detecting anaerobic threshold by gas exchange. J Appl Physiol 1986;60(6): 2020-2027.

12. ATS/ACCP. Statement on cardiopulmonary exercise testing. Am J Respir Crit Care Med 2003;167(2):211-277.

13. Jensen K, Muller HH, Schafer H. Regional confidence bands for ROC curves. Stat Med 2000;19(4):493-509.

14. Fluss R, Faraggi D, Reiser B. Estimation of the Youden Index and its associated cutoff point. Biom J 2005;47(4):458-472.

15. Jones NL, Killian KJ. Exercise limitation in health and disease. N Engl J Med 2000;343(9):632-641.

16. Puente-Maestu L, Garcia de Pedro J, Martinez-Abad Y, Ruiz de Ona JM, Llorente D, Cubillo JM. Dyspnea, ventilatory pattern, and changes in dynamic hyperinflation related to the intensity of constant work rate exercise in COPD. Chest 2005;128(2):651-656.

17. Loring SH, Garcia-Jacques M, Malhotra A. Pulmonary characteristics in COPD and mechanisms of increased work of breathing. J Appl Physiol 2009;107(1):309-314.

18. Liu P, Liu J, Yang W, Sun X. Application of $\mathrm{VO}_{2}$ in evaluating the heart and lung function of severe COPD patients. Inter J Respir 2011;31:334338.

19. Liu P, Liu J, Yang W, Sun X. Study of the characteristics of dynamic oxygen uptake in severe COPD patients during exercise. Inter J Respir 2011;31:672-677.

20. O'Donnell D E. Dynamic lung hyperinflation and its clinical implication in COPD. Rev Mal Respir 2008;25(10):1305-1318.

21. Peters MM, Webb KA, O’Donnell DE. Combined physiological effects of bronchodilators and hyperoxia on exertional dyspnoea in normoxic COPD. Thorax 2006;61(7):559-567.

22. Yetkin $\mathrm{O}$, Gunen H. Inspiratory capacity and forced expiratory volume in the first second in exacerbation of chronic obstructive pulmonary disease. Clin Respir J 2008;2(1):36-40.

23. Newton MF, O'Donnell DE, Forkert L. Response of lung volumes to inhaled salbutamol in a large population of patients with severe hyperinflation. Chest 2002;121(4):1042-1050.

24. O'Donnell DE, Fluge T, Gerken F, Hamilton A, Webb K, Aguilaniu $\mathrm{B}$, et al. Effects of tiotropium on lung hyperinflation, dyspnoea and exercise tolerance in COPD. Eur Respir J 2004;23(6):832-840.

25. Tashkin DP. Impact of tiotropium on the course of moderate-to-very severe chronic obstructive pulmonary disease: the UPLIFT trial. Expert Rev Respir Med 2010;4(3):279-289.

26. Vassaux C, Torre-Bouscoulet L, Zeineldine S, Cortopassi F, PazDiaz H, Celli BR, et al. Effects of hyperinflation on the oxygen pulse as a marker of cardiac performance in COPD. Eur Respir J 2008; 32(5):1275-1282.

27. Casanova C, Cote C, de Torres JP, Aguirre-Jaime A, Marin JM, Pinto-Plata $\mathrm{V}$, et al. Inspiratory-to-total lung capacity ratio predicts mortality in patients with chronic obstructive pulmonary disease. Am J Respir Crit Care Med 2005;171(6):591-597.

28. O'Donnell DE, Webb KA. The major limitation to exercise performance in COPD is dynamic hyperinflation. J Appl Physiol 2008; 105(2):753-755; discussion 755-757.

29. Barr RG, Bluemke DA, Ahmed FS, Carr JJ, Enright PL, Hoffman EA, et al. Percent emphysema, airflow obstruction, and impaired left ventricular filling. N Engl J Med 2010;362(3):217-227. 